\title{
AMBROSIA BEETLES AND THEIR CONTROL IN BRITISH COLUMBIA ${ }^{1}$
}

\author{
By D. L. MCMULLAN ${ }^{2}$
}

D. L. (Larry) McMullan is Chief Forester with British Columbia Forest Products Limited, a Coast firm employing 4,000 people in seven logging operations, four sawmills, a plywood plant and a green veneer plant. He holds the degree of Bachelor of Applied Science in Forestry Engineering having graduated from the University of British Columbia in 1934.

Mr. McMullan was born in Manitoba where he obtained part of his elementary schooling. He completed his public and high schooling at Salmon Arm in British Columbia. When he graduated from University, Mr. McMullan worked for a year as an Assistant Logging Engineer and then joined the British Columbia Forest Service. During the next eleven years he worked on forest surveys and regeneration and logging studies for that Provincial Government Department. Toward the end of this term of service he became Assistant District Forester in the Prince George District.

Mr. McMullan joined the British Columbia Forest Products Limited in 1946, shortly after the Company was formed. He assumed the position of Chief Forester and has directed the work of the Company's forestry department since that time.

Ambrosia Beetles are widely distributed throughout the world. However, for two reasons I am going to confine my remarks to the Coastal Region of British Columbia. In the first place, that is the region in which $I$ have had my experiences with the beetle. Second, if I were to discuss the problem and control as it affects all regions and talk about all of the painstaking research which has been done, I would probably extend this conference for several days.

In the time which I have at my disposal I shall discuss what we know about the insect, what the problem is with regard to damage and what control measures have been experimented with in the B.C. Coastal Regions.

\section{THE INSECT}

The Ambrosia Beetle is a small, hard-shelled insect which has a liking for unseasoned wood products. All commercial native species of wood are subject to attack. The adult beetles bore small round holes into the wood. These holes are about the size of the lead in a lead pencil, and due to their appearance, are frequently called pinworm holes. The insect does not eat the wood but constructs small pockets or offshoots from the main tunnels in which to lay eggs. As the wood is not eaten, the borings are ejected from the tunnel and appear on the surface of the wood or bark as a fine light-colored powder. It was once thought that the boring, for at least the initial stages, was done by the male beetle. But, recent observations by entomologists of the Science Service, who have been prying into the private life of the insect, indicate that the male

\footnotetext{
${ }^{1}$ Paper presented at the Forty-seventh Annual Convention of the Canadian Institute of Forestry, in Saskatoon, Saskachewan, October 5 th to 7 th inclusive, 1955.

${ }^{\circ}$ Chief Forester, British Columbia Forest Products Limited, Vancouver, B.C.
} 


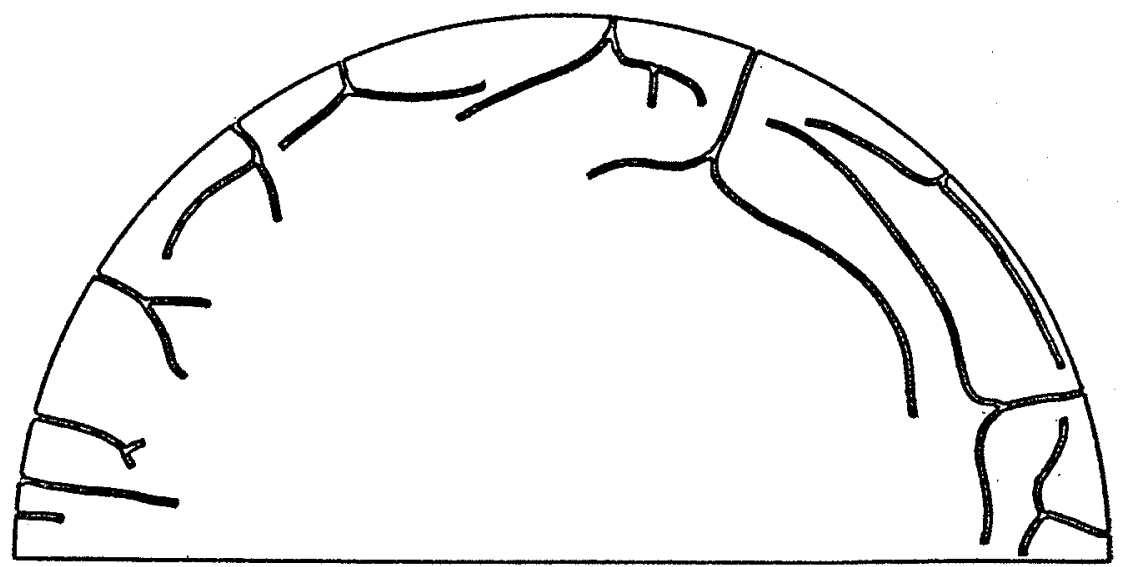

FIGURE 4

Typical Trypodendron tunnel system.

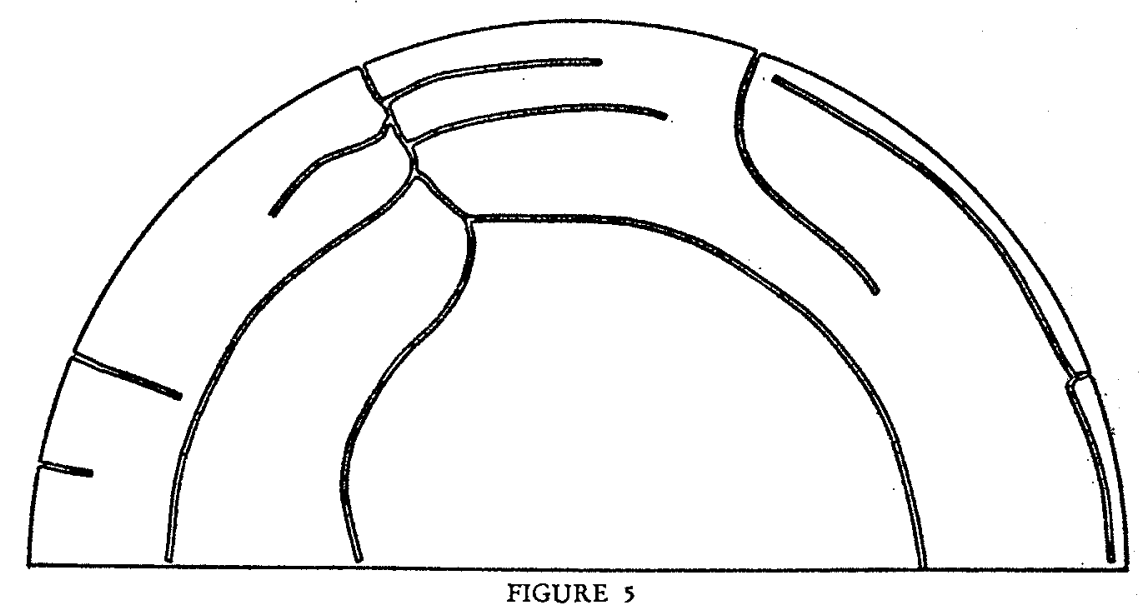

Typical Gnathotrichus tunnel system. The above are reproduced from sketches prepared by the Forear Biology Division, Science Service.

is a rather easy going fellow and leaves most of the work of burrowing to his spouse.

Intentionally, or otherwise, the adults carry the spores of certain fungi, mainly of the Ceratostomella or blue staining family, into their tunnels. The insect and larvae feed upon this fungi. According to F. P. Keen, of the United States Department of Agriculture, each species of beetle is said to have its own special ambrosial fungus. Apparently the moisture requirements of these fungi are quite exacting. If there is insufficient moisture the fungi does not grow and 


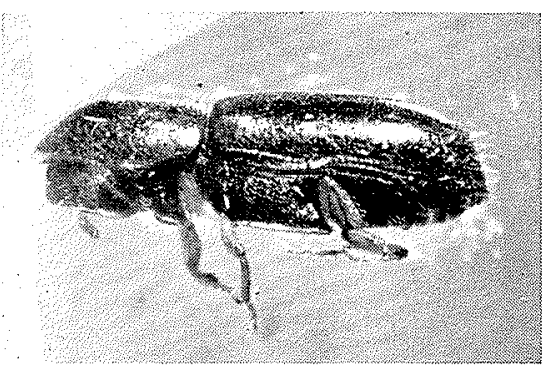

FIGURE 1: The Gnathotrichus adult. Magnification $\mathrm{x} 13$.

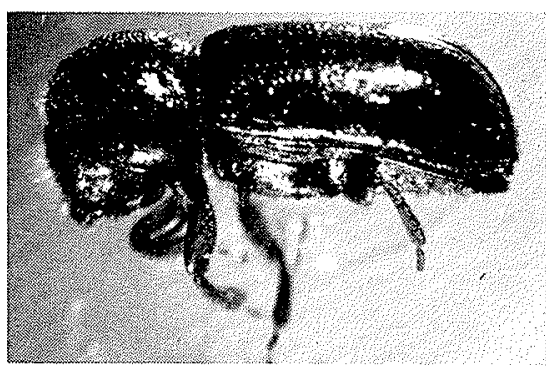

FIGURE 2: The Tryodendron adult. Magnification $\times 13$.

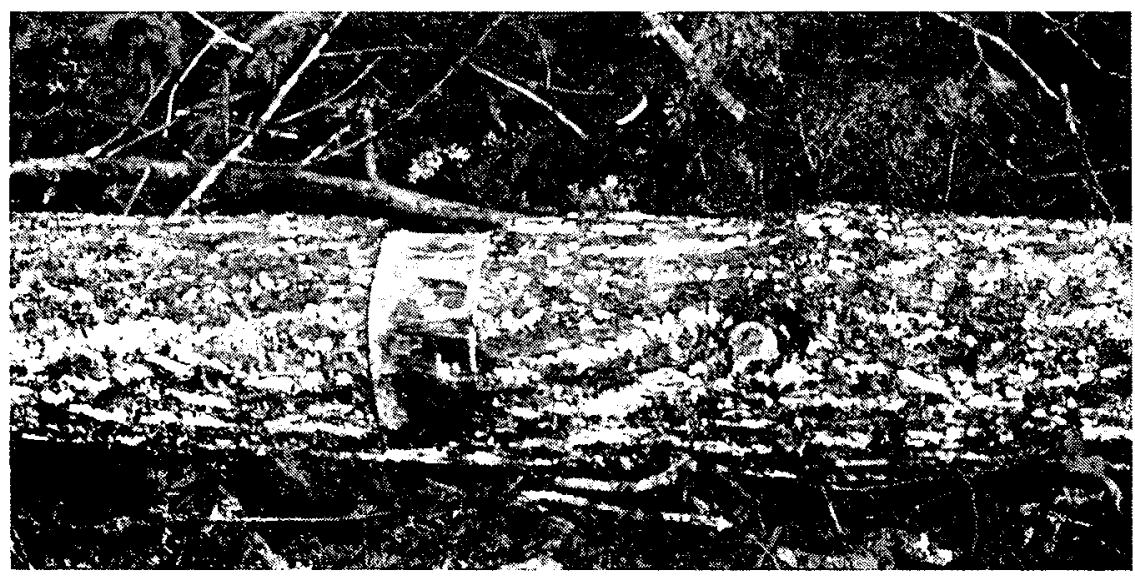

FIGURE 3: Boring dust on a freshly attacked log. Photograph by Science Service.

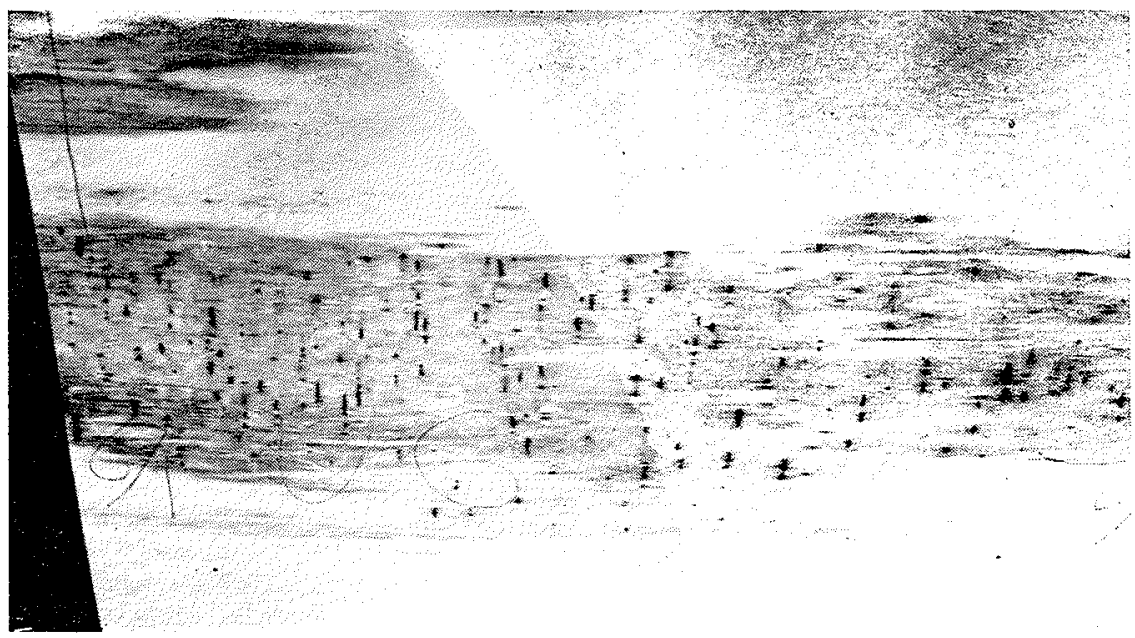

FIGURE 7: Sheer of Douglas fir veneer showing how a woods spriayed log is free of ambrosin attack in the areas protected by the toxic material. The infested area was probably the underside of the $\log$ and was missed in spraying. Note staining in vicinity of tunnels. Photograph by Science Service. 
so the insect, or at least the larvae, starves. On the other extreme, the fungi may grow too abundantly and the insect may smother in its own food supply. Because of the presence of the fungi and accompanying stain, the tunnels have their characteristic appearance.

The exacting moisture requirements of ambrosial fungi explains, at least in part, why seasoned wood is not attacked by the insect and why in certain tree species the borings are confined to the sapwood areas and in others the heartwood is attacked. Observations indicate that heaviest attack, especially by Trypodendron, our most prevalent species, occurs in partially seasoned wood. Timber felled in the summer or fall of one year and exposed to attack the following spring or summer appears more subject to attack than timber felled later on. In regard to species, the damage to Douglas fir is restricted to the sapwood areas which are usually confined to the outer 2 inches or less of the log. In the case of Western hemlock, where there is no pronounced sapwood and the moisture content of the wood is very high, the insect may penetrate to a depth of up to 5 or 6 inches.

Five species of ambrosia are found in the coastal areas of British Columbia. These are Trypodendron cavifrons, Gnathotrichus sulcatus, Gnathotrichus retusus, Platypus Wilsoni and Xyleborinus tsugae. Descriptions of the activities of these species will be confined to Trypodendron cavifrons and Gnathotrichus sulcatus because they cause by far the greater part of the damage in the region under discussion.

Trypodendron cavifrons is the worst offender, mainly because it occurs in the greatest numbers. The adults come out of hibernation in the duff when the ground temperature has risen to about $60^{\circ} \mathrm{F}$. This may take place any time in April or May depending upon weather conditions. They immediately attack logs and other unseasoned wood. The tunneling and egg laying extends over a period of about a month. Then about the end of June the surviving adults emerge to form a mild secondary fiight and move to other logs. The new adults leave their tunnels in the wood any time between late July and late October and go into the duff to hibernate. Recent observations indicate that the bulk of them hibernate in the duff under nearby standing timber.

Gnathotrichus sulcalus, though less numerous than Trypodendron, individually cause more damage. This is because their attack is more continuous and their depth of penetration is greater in wood species such as hemlock, which have a high moisture content. In favorable seasons this species, which hibernates in the wood, may be active from early April to late November. Also, while the Trypodendron prefers partly seasoned wood, the season of felling appears to make little difference to Gnathotrichus.

\section{Ambrosia Beetle Damage}

Ambrosia Beetle damage has been recognized for a long time but, I am afraid, is too often regarded as one of the normal hazards of the industry and it is felt that, like the weather, nothing can be done about it. One of the earliest records we have of the importance of the problem goes back to 1928. In that year, portions of some shipments of lumber from British Columbia to Australia were, on arrival, ordered destroyed under quarantine regulations because of the presence of live Ambrosia Beetles. During the ensuing depression years 


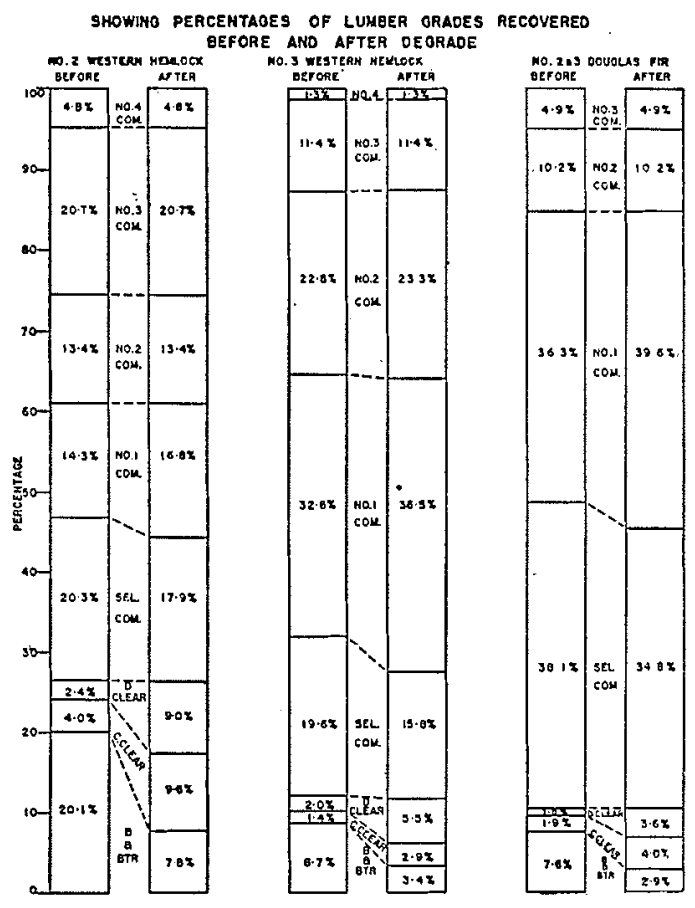

FIGURE 6

From the Forest Products Laboratories of Canada Report by C. F. McBride.

other shipments of lumber suffered similar treatment or met wtih expensive inspection and fumigation costs - all of which of the shipper could ill afford. However, we cannot blame Australia for wanting to stay clear of this pest. Australia has Ambrosia Beetles but not the same species we have. Even today, similar regulations are in effect and no lumber with any sign of ambrosia attack can be shipped to that country. However, we do feel that ther regulations are too stringent in that they apply to kiln dried lumber which, we are certain, is free from any live insects.

New Zealand and South African markets are also closed to any lumber having ambrosia damage. The United Kingdom importers accept this class of lumber but, unfortunately, the builders are strongly prejudiced against it so there is a limit to the amount of damaged lumber that can be shipped to this market. The United States grading rules are similar to our own but even here there is, at times, a tendancy towards being fussy about the presence of ambrosia holes. In general, there appears to be a trend in most markets against accepting infested lumber, even when kiln drying has killed all the insects.

Besides limiting our markets, other ways in which Ambrosia Beetles cause economic losses are:

(a) The scale of logs is reduced where appreciable ambrosia damage is present. (b) In the sawmill, time may be lost at the headsaw if a clear face is required. 
(c) Likewise, in the sawmill, there is liable to be loss in lumber production due to heavier slabbing and edging.

(d) Degrading of lumber with consequent loss in value can be quite severe.

(e) Sawmill revenues are decreased through production of more boards and dimension and less volume of timbers.

(f) In plywood and veneer plants the loss due to degrading can also be quite significant.

(g) Infected logs are undesirable for rayon pulp.

I am not aware of any thorough attempt having been made to assess these overall losses, but the annual loss to British Columbia is certainly in the hundreds of thousands of dollars and possibly in the millions. However, in 1949, an initial study was undertaken to determine the loss resulting from ambrosia attack on sawmill logs. This study was a joint effort by the Dominion Forest Insect Laboratory, the Dominion Forest Products Laboratory, and our own Company, British Columbia Forest Products Limited. A number of mild to lightly infected logs were run through our Victoria Sawmill and a dual grading made of the lumber - one as it was with ambrosia damage and one as it would have been without ambrosia damage. In this way a dollar value could be placed on the loss due to ambrosia damage. For the logs covered by this study the loss ranged from $\$ 1.20$ to $\$ 3.31$ per M.B.M. of lumber produced. It should be emphasized that these losses occurred in logs that were lightly infected and that they were all No. 2 and No. 3 grade. Greater losses could be expected with a heavier attack. None of these logs showed more than 31 holes per square foot of surface, whereas, 100 to 200 holes per square foot are not uncommon. Due to the nature of its attack, the beetle does the greatest damage in the clear lumber (or veneer) from the outside of the $\log$ and consquently the greatest degrade loss occurs in the highest grade logs. The effect of ambrosia tunnels on lumber grades can best be illustrated visually as shown by the accompanying chart. This chart is taken from the mill study I have just mentioned and shows very clearly how the lumber was degraded.

By way of an explanation, the British Columbia Lumber Manufacturers Association lumber grading rules, insofar as they deal with pinworm (Ambrosia Beetle) damages, are briefly:

B \& Better Clear - no pinworm holes are allowed.

C Clear - "a few scattered" holes are allowed. This may amount to a maximum of one per lineal foot of surface providing certain other defects are not present.

D Clear - "limited" holes are allowed. This permits a maximum of 20 to 30 holes per square foot but here again the number will depend upon the presence of other defects,

Selected Common Dimension - does not permit any pinworm holes.

Selected Common Boards and No. 1 Common Dimension - allow a "limited" number of holes.

No. 1 Common Boards - unlimited pinworm holes permitted.

Mr. L. B. Dixon, Chief Grading Inspector for the British Columbia Lumber Manufacturers Association, is well aware of the Ambrosia Beetle problem and has compiled some interesting figures which indicate the incidence of the pest in lumber produced in the Coastal Region of British Columbia. For 
the years 1952 to 1954 he has records to show the percentage of clear grades of lumber that had Ambrosia Beetle damage. These figures are taken from reports of his inspectors and give a representative sampling. The results for Douglas fir and hemlock lumber are shown in the following table:

\begin{tabular}{|c|c|c|c|c|}
\hline & \multicolumn{2}{|c|}{ Douglas Fir } & \multicolumn{2}{|c|}{ Western Hemlock } \\
\hline & C Clear & D Clear & C Clear & D Clear \\
\hline $\begin{array}{l}\text { Percent degraded from a higher } \\
\text { grade due to pinworm holes } \\
\text { Percent having pinworm holes but } \\
\text { not degraded due to this cause } \\
\text { alone }\end{array}$ & 5.2 & 10.8 & 11.7 & 22.1 \\
\hline $\begin{array}{l}\text { Total PERCENT Having } \\
\text { PINWORM DAMAGE }\end{array}$ & $\ldots 7.0$ & 14.8 & 13.5 & 26.1 \\
\hline
\end{tabular}

The monetary loss due to degrade from $\mathrm{B}$ and Better to $\mathrm{C}$ Clear amounts to only 2 or 3 percent. However, further degrade is very serious. To show what can happen, let us take as an example Douglas fir Finish - dry - flat grained $1^{\prime \prime} \mathrm{x} 12^{\prime \prime}$. If a piece which would otherwise grade B and Better had more than one pinworm hole per lineal foot it would be degraded to C Clear and decrease about $2 \%$ in value. If this same piece had "limited" pinworm holes it would degrade to D Clear and decrease about $27 \%$ in value. Should this same piece have heavy pinworm damage it could be degraded down to No. 1 Common and decrease as much as $64 \%$ in value. This latter would be an extreme case.

It is unfortunate that figures have not been compiled to permit calculating the overall loss suffered by our lumber mills due to degrade. However, it is obvious from these examples that this loss is very significant and that efforts to reduce it are fully justified.

Similarly, plywood producers suffer appreciable losses because, as with lumber, it is the high grade face stock from the outer part of the log that suffers the most damage. Top grade Douglas fir plywood face stock veneer must be free of worm holes and various other defects, but up to 12 patches are allowed on a $4^{\prime} \times 8^{\prime}$ sheet. This means that a veneer sheet, with too many holes to be eliminated with 12 patches, and which would otherwise go as top grade face stock, would be degraded to core or sheathing grade. Top grade $1 / 4^{\prime \prime}$ plywood is worth about $36 \%$ more than sheathing grade so the monetary loss due to ambrosia holes can be quite significant.

\section{What has Been Done to Combat the Problem}

Over the years a number of studies have been undertaken by entomologists and others. In 1933, as a result of the disastrous experiences in shipping ambrosia infected lumber to Australia, G. R. Hopping and J. H. Jenkins made a study of the effect of kiln temperatures and air-seasoning on the pest. This showed conclusively that appropriate kiln drying schedules killed all beetles. Air drying was not completely effective except with long drying periods.

Prof. K. Graham and W. G. Mathers experimented with chemical control methods over a period from 1935 to 1937 but had no success with the insecticides available at that time. 
In 1942, M. L. Prebble and K. Graham investigated the deterioration of felled and bucked timber caused by Ambrosia Beetles. This study identified the various species of Ambrosia Beetles present and indicated their relative importance. In addition, it showed the susceptibility of various tree species to attack, the probable effect of time of felling of the trees, as well as indicating the intensity of attack and depth of penetration that could be expected.

Also, in 1942, E. C. Boyes, of Bloedel, Stewart and Welch Limited at Port Alberni, carried out some studies. These showed that the presence of Ambrosia Beetles could cause a loss of up to $10 \%$ in log scale. Also, he estimated that lumber produced from infected logs could suffer a loss of up to $10 \%$ in value due to degrading.

In 1953, A. G. Brand of MacMillan and Bloedel Limited, using a number of hypothetical No. 2 and No. 3 logs, showed that losses in lumber value of from $4 \%$ to $18 \%$ could be expected due to Ambrosia Beetle damage.

Also, in 1953, Canadian Forest Products Limited commenced a study on its logging operations in the Nimpkish River area on Vancouver Island. This was prompted by general observations in the woods and also in the sawmills which indicated that very appreciable losses were being suffered as a result of Ambrosia Beetle attacks. In the sawmill, $60 \%$ of the lumber grade hemlock suffered some damage.

The first experimental control measure they attempted was by spraying logs with a benzene hexachloride emulsion, similar to one described elsewhere in this paper, and which was used successfully by British Columbia Forest Products Limited in 1952. For inexplicable reasons, the results were very disappointing.

Their next experiment was designed to check observations of their own and others that felled and bucked timber carried over winter into the next ambrosia season was more susceptible to attack than timber felled in the spring. In this experiment, six trees were felled each month, December to April inclusive, and periodically examined for Ambrosia Beetle attack. The final examination was made in September. In summary, the results were:

Trees felled in December averaged 60 holes per square foot;

Trees felled in January averaged 10 holes per square foot;

Trees felled in February averaged 3 holes per square foot;

Trees felled in March averaged 0.5 holes per square foot;

Trees felled in April averaged 0.5 holes per square foot.

These figures were rather startling and have resulted in Canadian Forest Products Limited issuing a directive to their logging camp management in the Nimpkish River area, directing that:

1) Before May 1st each year, priority in logging should be given to those settings which contain the highest proportion of lumber hemlock and which have been on the ground the longest.

2) The falling date of settings which contain a high proportion of lumber hemlock and which will not be logged before May should be delayed until March or later, to avoid attacks.

The results of Canadian Forest Products Limited study is interesting and gives a partial solution to the Ambrosia Beetle problem. At the same time it points up our lack of knowledge of the beetles' behavior because in opera- 
tions of British Columbia Forest Products Limited, farther south on Vancouver Island, we have observed quite appreciable attack on spring felled logs, though perhaps not as severe as on fall felled logs. Why is the behavior so different in different localities - is it due to climatic factors or something else?

Since 1947, British Columbia Forest Products Limited has contributed annual grants to the University of British Columbia, which have totalled $\$ 40,000$. These grants have been for the purpose of furthering the study of forest insect problems and have enabled the University to employ a Professor of Forest Entomology. Since 1948 this position has been filled by Dr. Ken Grabam who, in his research, has specialized in the study of the Ambrosia Beetle. During the past year, his efforts have been directed towards investigation of the chemical changes in wood in relation to Ambrosia Beetle attack. This study was prompted by the fact that although the beetle does not attack the live tree, the felled tree may become very susceptible to attack.

As the study progressed, Dr. Graham and his assistants were able to demonstrate that certain odorous substances could be extracted from susceptible logs and that these substances could be used to induce Ambrosia Beetle attack on normally non-susceptible logs. Also, they suspected that after the felling of a tree a non-odorous substance having an unpleasant taste breaks down into substances with an attractive odor and a palatable or at least neutral taste.

The next steps were to:

1) Provide for the fractionation and chemical identification of the constituents of the volatile odorous extracts.

2) Demonstrate the chemical differences between the volatile extractives of freshly felled logs and logs that have been down for some time.

3) Investigate flavors as distinct from odors, since the boring that is prompted by odors will not continue if taste is not satisfied.

4) Investigate the biochemistry of odor and flavor production in the bark and wood.

5) Identify specific substances that account for responses to odor and taste.

On the advice of Mr. Arthur Werner, of the Department of Chemistry, University of British Columbia, it was decided to use gaseous extraction in order to obtain the volatile extractives. Also, Mr. Werner introduced the principle of vapor-phase chromatography to fractionate the extractives. As far as we know, this was its first application to wood chemistry anywhere in the world. Special apparatus had to be designed and constructed as there was none in existence having the high degree of sensitivity required for this experiment. This work was carried out by Mr. Werner, with valuable assistance from the U.B.C. Department of Chemistry, and with financial help from the University, the Dominion Science Service and British Columbia Forest Products Limited. At this date I can report that, in spite of many obstacles, construction of the necessary apparatus has now been completed. As an indication of its sensitivity and efficiency, it is said to be able to separate one cubic centimeter of vapor, containing perhaps a dozen gases, into its separate constituents in a matter of 20 minutes.

It is quite probable that this apparatus will also benefit our industry by being of use in wood chemistry and wood utilization studies. 
With the aid of this apparatus we hope that Dr. Graham will be able to carry his research to a successful conclusion. At this point, it would be reasonable to ask, "how will this work aid in the control of the Ambrosia Beetle?" There are two possibilities:

1) By baiting with extractives which attract the beetle, and

2) By chemically treating the standing tree it may be possible to nullify the chemical changes that make the wood attractive to the beetle once the tree is felled.

In addition to his research on wood extractives that attract Ambrosia Beetles, Dr. Graham has for the past summer worked with Messrs. Chapman and Kinghorn, of the Forest Biology Division, Science Service. This team carried out field and laboratory studies of the Ambrosia Beetle. Dr. Chapman specialized in physiological studies of the insect. One part of these studies dealt with its flight habits and, I understand, confirmed the belief that it is capable of travelling several miles when in flight. Mr. Kinghorn studied wintering habits of the various species of Ambrosia Beetle, experimented with various toxic spray formulations and made observations on the susceptibility to attack of logs in the woods. As yet, the work of this team is incomplete, but we feel confident that its findings will eventually provide us with data which will be very useful in our attempts to minimize the damage caused by this pest.

In 1952, the first commercial application in British Columbia of an insecticide for the prevention of Ambrosia Beetle attack on logs was made by British Columbia Forest Products Limited at its Cowichan Division on Vancouver Island. On the recommendation of entomologists of the Science Service and the University of British Columbia, a special formulation with benzene hexachloride (commonly called B.H.C.) as the toxic base was used. As all the logs to be sprayed were in booms in Cowichan Lake, the Federal Department of Fisheries and the Provincial Game Department were consulted to insure that the spray would not create a serious hazard to fish.

The spray formulation consisted of:

4 pounds of $36 \%$ gamma isomer benzene hexachloride

1.6 gallons of Velsicol Ar-50

0.15 gallons of Antarox A-400

34 gallons of water.

This gave a concentration of $0.4 \%$ benzene hexachloride. In preparing the formulation it was found best to heat the Antarox to at least $120^{\circ} \mathrm{F}$. in order to hasten the dissolving of the benzene hexachloride crystals. Next the Velsicol and water were added.

In this solution the Antarox served as an emulsifying agent while the Velsicol was used as the oil carrier. After application of the spray to the logs, the water evaporates leaving the toxic agent in the oil carrier on the surface of the logs with a certain amount of penetration taking place.

On the advice of the entomologists, the logs were sprayed twice in order to give protection throughout the flight periods of the two main species of Ambrosia Beetles. The first application was made in early May and the second in early July.

In this initial spraying program some 1,200 M.B.M. of high grade Douglas fir peeler logs were sprayed. These logs were from trees that had been felled 
during the insects' hibernation period, so we were sure that there was no infestation prior to the initial spraying. Special observations were made of the logs when they went through the veneer plant early in 1953 and there was no degrading due to Ambrosia damage. As Ambrosia Beetles had been very numerous during the spring and summer of 1952 it was apparent that the spray had been effective in protecting the sprayed booms.

For this initial spraying project the cost was $21.2 \mathrm{c}$ per M.B.M. per application and this cost included $4.2 \mathrm{c}$ for miscellaneous charges in preparing equipment etc., part of which was used in succeeding years.

Encouraged by the results of our 1952 program of spraying logs in booms, we have each year since carried on increasingly larger programs reaching a maximum of over 20,000 M.B.M. gross coverage in 1955 . In addition, we have embarked on experimental projects with felled and bucked timber and with different spray formulations. Without going into all the details it will be sufficient to summarize our experiences and observations to date as follows:

1) It is essential to apply the first spray prior to the initial ambrosia flight in the spring.

2) Best results will be obtained if the spray is applied when the logs are dry.

3) The first Ambrosia Beetle flight may develop very quickly once the weather is favorable. As favorable weather may follow wet weather by only a few days, it is essential that no time be lost in applying the spray. On one or two occasions we have had to stop spraying because the active beetle population built up too fast.

4) Benzene hexachloride has a very musty and lasting odor, but unfortunately it appears to have no repellent effect on Ambrosia Beetles.

5) With the exception of the ends of the logs, it is essential that every bit of exposed surface be sprayed in order to obtain complete protection. They do not seem to attack the end of the logs.

6) Logs along rights-of-way, through standing timber, appear to be the most susceptible to attack, probably because of higher humidity in such areas.

7) In our 1953 experimental spraying of felled and bucked timber, we found that it cost about $45 \mathrm{c}$ per M.B.M. per application to intensively spray rightof-way logs wih a fire pump. Selected Peeler logs were sprayed with back-pack pumps at a cost of 49c per M.B.M. per application.

8) The protection given to felled and bucked logs has been inadequate because of the difficulty of getting the spray all around the logs.

9) In 1953 we sprayed a small batch of logs with benzene hexachloride in wettable powder form. It was mixed in water with no emulsifier or oil carrier and heating was not required. The results were inconclusive, but we suspect that this formulation would be subject to leaching. Also, the wettable powder was difficult to keep in suspension in the spray solution.

10) In 1954 we tried using Diesel Oil in place of Velsicol on one boom. Three times as much Diesel Oil was used and the quantity of emulsifier had to be doubled. This gave a cheaper formulation, as Velsicol costs about 
eight times as much as Diesel Oil, and the effectiveness of the emulsion as a protective agency appeared to be quite satisfactory.

11) Also in 1954 we tried using Corum 44 on one boom of logs. Corum 44 is a heavy oil and it was mixed in with our standard formulation. The heavier oil was used with the idea of getting something that would have better residual qualities. Results were inconclusive.

12) In 1955 our chemical supplier provided us with a concentrate of benzene hexachloride, Antarox and Velsicol which was used in most of our spraying. Our main formulation was in the proportions of:

Commercial concentrate
Diesel Oil

Use of the commercial concentrate saved considerable time in mixing.

13) Also in 1955 some booms were sprayed with a formulation similar to the above but with the additional Antarox omitted in order to give a faster breaking emulsion.

14) Some of the entomologists felt that better results would be obtained by using a fast breaking emulsion which would not wet back thus concentrating the toxic agent on the outside of the logs rather than attempting to get some penetration. Also, it is thought that this would give some fumigating effect. They recommended using ammonium oleate in place of Antarox in the formulation given above. Upon application the ammonia volatalizes and the residue acts as a sticker for the benzene hexachloride. At time of writing, results of our 1955 spraying are not available.

15) As a result of experience in spraying and mixing techniques and the use of diesel oil, commercial concentrate of benzene hexachloride, Antarox and Velsicol, etc., we brought our lake spraying costs down to less than 14c per M.B.M. per application in 1955.

16) When spraying is in progress it is essential to keep the mixture agitated, especially where wettable powder or ammonium oleate are being used. In power spraying projects this is done by pumping part of the liquid back through the tank by use of a pressure bypass valve.

17) Several of the chemical companies have taken quite an interest in these Ambrosia Beetle control projects and are experimenting with various chemicals.

18) Ambrosia Beetles have also posed a problem for our Cowichan Lake Sawmills where fairly heavy attack has occurred in fresh green lumber. It has been necessary to control the beetle by spraying or dipping the lumber. This control has been quite effective.

19) On a number of booms we have tried increasing the benzene hexachloride concentration up to $0.8 \%$ but there has been no significant increase in effectiveness. It appears that if the ambrosia population is extremely heavy there are always some beetles that get through regardless of the poison concentrate.

20) Due to an unknown factor, or perhaps combination of factors, some 
sprayed booms of logs have been attacked. However, on the whole, the spray has been effective. We are satisfied that it is well worth the expense of around 30c per M.B.M. for two applications to avoid, or at least greatly reduce, potential losses of from one to several dollars per thousand board feet.

21) Losses due to Ambrosia Beetle damage can be reduced by keeping logs inventories to a minimum during the spring and summer months. This is often difficult on the coast because, in order to permit continuous operation of the plants, log inventories are usually being built up at this time of year so as to meet probable cessation of logging operations due to fire closures in the summer and shutdowns due to snow in the winter. Furthermore, where the topography is such as to require the use of skyline logging equipment, the settings are large and the elapsed time between commencement of falling and completion of yarding may be close to a year. In the Interior parts of the Province log stocks are usually fairly light in the summer. This probably explains why the Ambrosia Beetle, though present, is not regarded as being too serious a problem in the Interior.

22) The potency of the spray decreases with time and sprayed logs that are not cut up until fall are more liable to receive some damage.

This, in brief, is the picture of the Ambrosia Beetle problem in British Columbia. We have learned quite a bit about the pest during the past few years and have had some measure of success in reducing its depredations. Spray formulations have given fairly good protection for logs in booms. Also, by exercising what control is possible over log inventories and time of felling, the amount of damage can be lessened. However, we still have a long way to go but are hopeful that research now being carried out will prove fruitful. Our ultimate goal is control which will be effective to the point where the drain on our industry's economy will be insignificant.

\section{REFERENCES}

1. DEMBICKI, H. 1953. Report on chemical control of Ambrosia Bectle degrade. Private report prepared for British Columbia Forest Products Limited.

2. GRAHAM, K. and BOYES, E. C. Pinworms in lumber. British Columbia Lumberman, August, 1950.

3. GRAHAM, K., KINGHORN, J. M. and WEBB, W. E. Measurement of a damage index in logs infested by Ámbrosia Beetles. British Columbia Lumberman, August, 1950.

4. HOPPING, G. R. and JENKINS, J. H. 1933. The effect of kiln temperatures and air seasoning on Ambrosia insects (Pinworms). Dominion Forest Service Circular 38.

5. KEENE, F. P. 1952. Insect encmies of western forests. U.S. Department of AgricultureMiscellaneous Publication No. 273.

6. McBRIDE, C. F. 1950. Th effect of Ambrosia Beetle damage upon lumber value. Forest Products Laboratories of Canada.

7. PATTERSON, G. A. 1954. Ambrosia Bectle control measures in the Nimpkish Valley during 1953. Private report prepared for Canadian Forest Products Limited.

8. PREBBLE, M. L. and GRAHAM, K. 1943. Investigations of Ambrosia Beetle damage in felled and bucked timber on Vancouver Island, B.C. Unpublished report. 